\title{
POR QUÉ LA CIENCIA DEBE SER «GAYA». SOBRE LA CUESTIÓN DEL PERSPECTIVISMO EN NIETZSCHE
}

Why science should be «joyful».

On Nietzsche's perspectivistic question

\author{
Carlo Gentili
}

Universidad de Bolonia

RESUMEN: ¿Cuál es la jovialidad de la gaya ciencia? Aparte de la obvia referencia a la poesía de los trovadores (que Nietzsche sólo a posteriori reivindica), define a un tipo de ciencia que es capaz de reír sobre sus pretensiones de conocimiento absoluto. Éste es el origen de lo que más tarde llamará el perspectivismo. Cada trozo de conocimiento depende de la perspectiva bajo la cual observamos el objeto; esta tesis debe ser examinada cuidadosamente puesto que tiene implicaciones para su propio punto de vista. La verdad no es otra cosa más que el conjunto infinito de perspectivas particulares. Este resultado escéptico de la filosofía de Nietzsche es la radicalización de la doctrina kantiana de la cosa en sí. Las consecuencias que extrae Nietzsche de él contribuyen a destruir el antropocentrismo. Todas las referencias a los animales inferiores (moscas, ranas, gusanos, mosquitos, hormigas) sirven para romper la ilusión de que el ser humano sea el punto más alto de la creación. La destrucción paralela de las ilusiones de una ciencia humana, demasiado bumana, es el tema principal del capítulo quinto de La gaya ciencia, añadido en la segunda edición de 1887.

Palabras clave: conocimiento - cosa en sí - antropocentrismo - perspectivismo - ciencia

ABSTRACT: What is the gaiety of the Gay Science? Apart from the obvious reference to troubadours' poetry (which Nietzsche only later recalls), it defines a science which is able to laugh at its own claim to absolute knowledge. This is the source of what Nietzsche will call perspectivism some years later. Each piece of knowledge depends on the perspective from which we look at the object; this assumption itself must be carefully considered for it implies its own point of view. Truth can be nothing but the indefinite whole of single perspectives. This skeptical result of Nietzsche's philosophy is the radicalization of Kant's doctrine of the thing-in-itself. The consequences Nietzsche draws from it lead to the fading of anthropocentrism. All the references to inferior animals (flies, frogs, worms, mosquitoes, ants) serve to discard the delusion that human beings are the highest point of creation. The parallel destruction of the illusions of a buman, all too buman science is the main subject of the fifth chapter of Gay Science, added to the second edition in 1887.

Keywords: Knowledge - Thing-in-Itself - Anthropocentrism - Perspectivism - Science

\section{CONVIÉRTETE EN LO QUE ERES: UN «SABIO POR JOVIALIDAD» [GAY SABER]}

En referencia al sentido que se debe asignar al título de la obra publicada, en primera edición, en agosto de 1882, Die fröhliche Wissenschaft, Nietzsche se muestra inesperadamente parco en información. Al menos hasta enero/febrero de 1882, piensa en un apéndice de Morgenröthe, del que prevé, según escribe a Heinrich 
Köselitz el 25 de enero de 1882, «los libros VI, VII y VIII», reservándose para el invierno posterior «los libros 9 y 10» (KSB VI 159). Contrariamente a dichas intenciones, el 5 de febrero escribe de nuevo a Köselitz contándole que se ha visto obligado a postergarlo por la discusión del concepto de causalidad «en el 'Libro 9' de Aurora» (KSB VI 167) que, por tanto, se considera ya como escrito ${ }^{1}$.

Sin embargo, el 8 de mayo, Nietzsche comunica inesperadamente a su propio editor, Ernst Schmeitzner, lo siguiente: «En otoño, puede contar con un manuscrito mío titulado La gaya ciencia (iiicon muchos epigramas en verso!!!)» (KSB VI 191). Es la primera vez que aparece este título. Nietzsche decide más tarde apresurar el trabajo de modo que, el 20 de agosto, desde Tautenburg (en pleno «idilio» con Lou Salomé), anuncia a Köselitz el envío de la "primera copia» del libro recién publicado (KSB VI 238).

En las cartas no se encuentra una explicación clara del cambio de título ni de su significado. Es evidente que alude a la poesía provenzal. En un fragmento (11[337]) de la primavera-otoño de 1881 se lee, bajo el título Gaya Scienza, una lista de composiciones trovadorescas (Albas, Serenas, Tenzoni, Sirventes, etc.) con sus explicaciones (KSA IX 57). La gaya scienza es, además, el subtítulo de la Fröhliche Wissenschaft, y a esta expresión recurre en el aforismo 377 (Wir Heimatlosen) del Libro V, agregado en la segunda edición de 1887 (KSA III 628): a la misma y a otras equivalentes - gaya ciencia, gay saber- Nietzsche recurrirá con frecuencia, sobre todo después de 1882.

Sin embargo, en ese momento parece ser una referencia puramente nominal. Sólo observando hacia atrás la Fröhliche Wissenschaft Nietzsche mostrará haber buscado en los provenzales un modelo de moral antitético a la moral tradicional. Así, por ejemplo, en una observación de Jenseits von Gut und Böse, después de distinguir el deseo de libertad que caracteriza la moral de los esclavos del «arte y el entusiasmo en la veneración, en la entrega» que es indicio "de un modo aristocrático de pensar y valorar», Nietzsche afirma:

Ya esto nos hace entender por qué el amor como pasión —es nuestra especialidad europea- tiene que tener sencillamente una procedencia aristocrática: como es sabido, su invención es obra de los poetas-caballeros provenzales, de aquellos magníficos e ingeniosos hombres del "gai saber», a los cuales debe Europa tantas cosas y casi su propia existencia².

En la reexaminación de la obra que Nietzsche propone en Ecce homo, la explicación del título se somete, sin embargo, a la estructura formal de la obra, es decir, a la presencia de las composiciones poéticas, especialmente de los Lieder des Prinzen Vogelfrei: esto recordaría «el concepto provenzal de la gaya scienza, aquella unidad de cantor, caballero y espíritu libre que hace que aquella maravillosa y temprana cultura de los provenzales se distinga de todas las culturas ambiguas»; en particular, el último Lied, Al Mistral — «una desenfrenada canción de danza en la que, icon permiso!, se baila por encima de la moral»— sería «un

1. La sorprendente aceleración es ciertamente debida, como supone Curt P. Janz, al hecho de que Nietzsche elabora notas preexistentes; cf. C. P. Janz, Friedrich Nietzsche. Biographie, vol. 2: Die zehn Jahre des freien Philosophen, Frankfurt a. M./Wien, ${ }^{2} 1994$, pp. 105-106.

2. KSA V 212 (MBM, trad. de A. Sánchez Pascual, Madrid: Alianza, 2003, p. 240). 
provenzalismo perfecto» (ein volkommer Provençalismus) $)^{3}$. Estas palabras confirmarían la idea de que Nietzsche mira a los provenzales, sobre todo, como a un modelo moral: de una moral aristocrática. Si ésta es una consecuencia de las bases puestas en la Fröhliche Wissenschaft, el propósito original era, sin embargo, diferente: el tema central del libro es, de hecho, el del conocimiento.

Para respaldar esta hipótesis, debemos volver a las cartas, en las cuales Nietzsche parece declarar, ante todo, una profunda afinidad entre el libro y sí mismo. El 10 de junio de 1882, desde Naumburg, escribe a Lou Salomé: «Actualmente, tengo una gran necesidad de montañas y de bosques de frondosos árboles: $\mathrm{La}$ gaya ciencia, más aún que la salud, me empuja a la soledad» (KSB VI 203). La atmósfera que aquí se evoca parece ya la del Zaratustra; de hecho, remite al entrelazamiento de las dos obras. En el aforismo 342 (Incipit tragoedia), que cierra la primera edición y es retomado literalmente al principio de Zaratustra, Nietzsche escribe: «Cuando Zaratustra tenía treinta años abandonó su patria y el lago Urmi y marchó a las montañas. Allí gozó de su espíritu y de su soledad y durante diez años no se cansó de hacerlo» (KSA III 571).

Si el Zaratustra es el libro de la predicación, la Fröhliche Wissenschaft es el libro en el cual se acumula la sabiduría que es el presupuesto de la predicación. En conclusión, es la obra en la que Nietzsche se convierte en aquello que es. No es una casualidad que esta expresión recurra a menudo en este período. En una carta a Lou, escrita desde Naumburg el 10 de junio, concluye: «Píndaro dice en un cierto punto: 'Conviértete en lo que eres' (werde der, der du bist)»". El verso, de las Píticas de Píndaro (II, 72), lo conoce desde la juventud, cuando lo usa como lema de la disertación De Laertii Diogenis fontibus, premiada por la Facultad de Filología de Leipzig y luego publicada, en dos partes, en el Rheinisches Museum. En aquel periodo, Nietzsche se servía de él como una especie de refrán en sus comunicaciones con los amigos. Como es bien sabido, el verso de Píndaro inspirará el subtitulo de Ecce homo: Cómo se llega a ser lo que se es (Wie man wird, was man ist $)^{5}$. Pero, a la altura de la Fröhliche Wissenschaft, el lema se carga de

3. KSA VI 333-334 (EH, trad. de A. Sánchez Pascual, Madrid: Alianza, 2003, p. 102). Mientras escribe estas palabras, Nietzsche tiene tal vez en mente lo que había observado en el prefacio a la segunda edición de $F W$ : «Pero quien pudiera, ciertamente me perdonaría aún más aquella pizca de locura, de desenfreno, de 'gaya ciencia': aquel puñado de canciones, por ejemplo, que esta vez se añaden al libro - canciones en las que un poeta hace burla de todos los poetas de una forma difícilmente perdonable» (KSA III 346).

4. KSB VI 203. También poco después, en otra carta a Salomé de finales de agosto: «Por último, mi querida Lou, el antiguo, profundo y cálido ruego: iconviértase en lo que es! (werden Sie, die Sie sind!)» (KSB VI 247).

5. El verso de Píndaro está difusamente presente en toda la obra de Nietzsche. Por ejemplo, en la Tercera intempestiva (Schopenhauer als Erzieher) aparece entre las preguntas que el "gran hombre» dirige a sí mismo: «¿Por qué vivo?, ¿́qué enseñanza debo extraer de la vida?, ¿̇cómo me he convertido en lo que soy (wie bin ich so geworden wie ich bin) y por qué sufro por este ser-así?» (KSA I 374). Según Karl Löwith, en el subtítulo de Ecce Homo la máxima aludiría a la doctrina del eterno retorno de lo igual y asumiría un preciso sentido anticristiano, instaurando por tanto una relación oximórica con el título: éste se contrapone de hecho «a la pretensión cristiana de devenir-nuevo y devenir-otro en virtud de una conversión y de un renacimiento». Si «Nietzsche-Zaratustra» renace en virtud de una conversión, llegando a ser el maestro del eterno retorno, esto acontece sin embargo «no por una nueva y diferente vida en Cristo, sino por la vida siempre idéntica del mundo que, como un círculo eterno, en su devenir retorna a sí mismo" (K. Löwith, Nietzsches Philosophie der ewigen Wiederkehr des Gleichen, en Sämtliche Schriften, vol. 6: Nietzsche, Stuttgart: Metzler, 1987, p. 257). 
un sentido completamente específico. En un fragmento (11[297]) de la primavera-otoño de 1881 (cuando todavía piensa en la prosecución de Morgenröthe), se puede leer: "Tiende siempre a convertirte en lo que eres (Werde fort und fort, der, der du bist) - ieducador y plasmador de ti mismo!» (KSA IX 555). En la carta en la que anuncia a Köselitz el envío de la primera copia del libro (20 de agosto de 1882) es donde, en la despedida final del amigo, se precisa el carácter de esta educación y plasmación: «iCuídese! No la tomemos con la vida, intentemos, por el contrario, llegar a ser cada vez más lo que somos (Wir wollen [...] immer mehr werden, die wir sind) — individuos 'sabios por jovialidad' (die 'fröhlichWissenden')» (KSB VI 239). Finalmente, el hecho de que el verso de Píndaro tenga una importancia específica precisamente en relación con la Fröhliche Wissenschaft queda demostrado con su inclusión en el texto; en el aforismo 270, suena como una respuesta a la pregunta contenida en el título: Was sagt dein Gewissen? («¿Qué dice tu conciencia?»): «Debes llegar a ser lo que eres»(Du sollst der werden, der du bist) (KSA III 519).

Por tanto, podemos fijar dos puntos. En primer lugar, Nietzsche busca aquí una filosofía que responda a sus propios problemas personales. En este sentido, la Fröhliche Wissenschaft es una alegre toma de conciencia de la superación del terrible periodo - marcado por la dificultad en las relaciones personales y por la enfermedad- que había producido Menschliches, Allzumenschliches y sus apéndices ${ }^{6}$. Una clara demostración de este hecho es el prefacio de la segunda edición, en el cual Nietzsche habla explícitamente de una «ebriedad de la convalecencia» (KSA VI 345) y se pregunta sobre el papel de la enfermedad y de su superación, en la composición del libro, llegando a suponer una «filosofía de la propia persona» (Philosophie seiner Person) ${ }^{7}$. La búsqueda de esta filosofía se había cumplido claramente en el signo del werde der, der $d u$ bist.

Más cercana a los objetivos de nuestro estudio es la opinión expresada recientemente por E. Müller, Die Griechen im Denken Nietzsches, Berlin/New York: de Gruyter, 2005, p. 215, según el cual Nietzsche hace del verso de Píndaro «una de sus máximas filosóficas personales»; Müller afirma estar de acuerdo (ibid., n. 497) con la opinión de I. Christians, «Schauspieler, Maske», en H. Ottmann, Nietzsche-Handbuch Leben-Werk-Wirkung, Stuttgart/Weimar: Metzler, 2000, p. 323, según el cual la máxima pindárica asume en Nietzsche el sentido de contraposición con el lema délfico «conócete a ti mismo", transformado por la tradición platónica en una exigencia de autoconocimiento filosófico. El hecho de que Nietzsche utilice el verso de Píndaro en función de la exigencia de una «filosofía personal» asume para FW, como veremos en breve, una importancia determinante.

6. El 2 de julio, desde Tautenburg, Nietzsche anuncia con alegría a su hermana Elisabeth la conclusión de la redacción de la Fröhliche Wissenschaft: «El manuscrito está completamente listo. Es una bonita sensación de victoria, iconsiderando los 6 años!» (KSB VI 216). Él calcula aquí la duración del periodo de tribulación a partir de los primeros esbozos de Menschliches, Allzumenschliches.

7. KSA III 347. Es posible imaginar que Lou Salomé haya tenido un papel en la definición de esta forma filosófica; o, cuando menos, que ella misma se lo haya imaginado. Es lo que se deduce de una carta de Nietzsche (16 de septiembre de 1882) en respuesta a una carta de Lou, que lamentablemente no se ha conservado: «Mi querida Lou —escribe Nietzsche—, su idea de una reducción de los sistemas filosóficos a actos personales de sus autores es justo una idea salida del 'cerebro fraternal' [en realidad, Geschwistergehirn: 'mente hermana']». Después de este reconocimiento, sin embargo, Nietzsche restablece enseguida, por así decir, el orden de precedencia: «Yo mismo he expuesto en Basilea la historia de la filosofía antigua en este sentido, yo gustaba de decir a mis auditores: 'Este sistema está confutado y muerto - pero la persona que está detrás de él es inconfutable, la persona no se puede dejar morir - por ejemplo Platón' (KSB VI 259). A pesar de que Nietzsche prefiera, en esta ocasión, citar como ejemplo a Platón, su referencia evidente es al escrito no publicado Die Philosophie im tragischen Zeitalter der Griechen (1873), en cuyos prefacios se lee: «Pondré de relieve, para cada sistema, solamente los 
En segundo lugar, tenemos así los contenidos de esta filosofía de la propia persona: se trata, ciertamente, de la filosofía de los fröhlich-Wissenden. Esta filosofía adquiere su sentido específico — su Fröhlichkeit - en relación directa con la poesía. Puesto que se ponen en el mismo plano de la filosofía, los suplementos poéticos modifican su sentido; la ciencia gaya es, justamente, la filosofía que adquiere la ligereza de la poesía. Este acercamiento de dos elementos en apariencia antitéticos - la ligereza de la poesía y la ponderación de la filosofía- se inclina hacia uno de los temas decisivos de la Fröhliche Wissenschaft: el de la locura (piénsese en el aforismo 125: Der tolle Mensch). A veces, parece que Nietzsche utilice el término locura en un sentido cercano a la jovialidad [gay saber]. En una carta enviada desde Tautenburg, el 27-28 de junio de 1882, escribe a Lou: "Ahora le cuento esto para que usted se ría. Soy siempre humano, demasiado humano, y mi necedad [Thorheit] crece a la vez que mi sabiduría [Weisheit]. / Esto me recuerda mi Gaya ciencia» (KSB VI 213). Necedad es, quizás, una traducción demasiado fuerte del término Thorheit que indica, en todo caso, la necedad del loco. Lo que interesa subrayar aquí es el acercamiento de Thorheit y Weisheit como el rasgo fundamental de la gaya ciencia. La referencia puntual de Nietzsche remite al aforismo (342: Incipit tragoedia) que cierra la primera edición del libro. Ahí escribe:

iMira! Estoy hastiado de mi sabiduría (Weisheit) como la abeja que ha recogido demasiada miel, tengo necesidad de manos que se extiendan, quisiera regalar y repartir hasta que los sabios (die Weisen) entre los hombres hayan vuelto a regocijarse con su locura (Thorheit), y los pobres, con su riqueza ${ }^{8}$.

Esta locura de la que los sabios deben regocijarse da a la ciencia su ligereza: se convierte con esto en gaya ciencia. En el prefacio de la segunda edición, Nietzsche reconsidera su propio camino de vida, presentando el nuevo horizonte conquistado como el fruto de ese "gran dolor» que es «el extremo liberador del espíritu»; éste «obliga, a nosotros los filósofos, a descender a nuestras últimas profundidades y a desembarazarnos de cualquier confianza (Vertrauen)» (KSA III 350). Liberados así, a través del dolor, de las ilusiones, los filósofos pueden dirigirse a una nueva percepción de la vida, no más ofuscada:

Desde dichos abismos, desde dicha grave enfermedad, también desde la enfermedad de la grave sospecha, se regresa renacidos, con la piel cambiada, más susceptibles, más maliciosos, con un gusto más sutil para la alegría, con un paladar más fino para todas las cosas buenas, con sentidos más jocosos, con una segunda y más peligrosa inocencia en la alegría, más infantiles y al mismo tiempo cien veces más refinados de lo que jamás habíamos sido antes (KSA III 351).

elementos que son parte de una personalidad, y entran en aquel aspecto inconfutable e indiscutible, que la historia tiene el deber de conservar»; y además: «Han sido elegidos, sin embargo, las doctrinas en las que vibra todavía de la forma más fuerte el elemento personal de un filósofo» (KSA I 801 y 803). En 1894, en su libro Nietzsche in seinen Werken, Salomé publicó la carta de Nietzsche como una suerte de prólogo; cf. L. Andreas-Salomé, Nietzsche in seinen Werken, Franfurt a. M.: Insel, 22000, pp. 24-25 (el manuscrito de la carta está reproducido en facsímil; el texto se encuentra en el apéndice en las pp. 29899). Sobre la Fröhliche Wissenschaft como el «libro más personal» de Nietzsche, cf. J. Salaquarda, «Die Fröhliche Wissenschaft zwischen Freigeisterei und neuer 'Lehre'»: Nietzsche-Studien 26 (1997), 170 s. 8. KSA III 571; cf. Za, KSA IV 11. 
La ligereza puede, por tanto, nacer solamente del abismo, de la profundidad, del dolor. Nietzsche sabe bien, desde Geburt der Tragödie ${ }^{9}$, que esta experiencia pertenece a los griegos, y puede por tanto concluir el prefacio con la célebre exlamación:

¡Oh, estos griegos! Ellos sí que sabían vivir: para vivir es necesario detenerse valerosamente en la superficie, en el surco, en la piel, adorar la apariencia, creer en las formas, sonidos, palabras, ien todo el Olimpo de la apariencia! Estos griegos eran superficiales - ipor profundidad! (Diese Griechen waren oberflächlich — aus Tiefe)! ${ }^{10}$.

Ser superficiales por profundidad: unidas ligereza y ponderación, alegría y seriedad, risa y dolor; con esto hemos definido la densa relación de significados estratificados en el título Die fröhliche Wissenschaft.

\section{EL «MUNDO DE LAS HORMIGAS» Y LA COSA EN SÍ}

Una vez establecido el sentido de la expresión gaya ciencia queda por entender qué es lo que mueve a la risa, qué marca el paso de la seriedad a la jovialidad. En este caso, somos más afortunados, puesto que Nietzsche nos lo dice inmediatamente en el aforismo 1 ( Die Lehre» vom Zweck des Daseins); este aforismo puede considerarse el lugar de la definición de los contenidos de la Fröhliche Wissenschaft. No obstante, pocos son los que han visto que este aforismo debe situarse en el contexto de aquella compleja idea, indicada con el término perspectivisimo, que Nietzsche lleva a término en los años sucesivos y que tiene como premisa la crítica del antropocentrismo. En el aforismo, Nietzsche sostiene que los criterios que presiden la conservación de la especie son completamente independientes de cualquier juicio moral: «También el más perjudicial de los hombres sea quizás, de cualquier modo, el más útil en orden a la corservación de la especie» (KSA III 369). Sucumbir a los mejores o peores anhelos no impedirá ser considerado «el promotor y benefactor de la humanidad» y permitirá conservar tanto a los propios «aduladores» como a los propios «escarnecedores». Pero, en ambos casos, no se encontrará nunca quien sepa mofarse de nosotros como individuos únicos, quien sepa hacernos sentir, "como requeriría la verdad», nuestra «ilimitada abyección de mosca y rana (Fliegen- und Frosch-Armseligkeit)» (KSA III 370). Lo que Nietzsche quiere decir es que, dado que la verdad es enunciada por individuos, nadie es capaz de elevarse a aquel horizonte desde el cual la verdad aparece como la enunciación de un individuo que, por tanto, se ubica, en el contexto de la vida biológica, en el mismo plano que la enunciación de cualquier ser viviente. Así pues, la aspiración humana a la verdad no es diferente o más digna que la aspiración a la verdad de cualquier otro ser viviente. Este tema no es nuevo en Nietzsche y se pueden seguir sus orígenes y su desarrollo en sus referencias a la vida biológica. La mosca y la rana tienen su precedente en el mosquito citado en

9. Valga, para todo, la exclamación que cierra Die Geburt der Tragödie: «iCuánto tuvo que sufrir este pueblo, para poder llegar a ser tan bello!» (KSA I 156).

10. KSA III 352. La frase es reproducida literalmente en Nietzsche contra Wagner (KSA VI 439). 
un escrito inédito de 1873, Ueber Wahrheit und Lüge im aussermoralischen Sinne. Después de comenzar el escrito con la fábula de los «animales inteligentes» que, «en un rincón remoto del universo», habían inventado el conocimiento y habían desaparecido un minuto después - «el minuto más altanero y falaz de la 'Historia Universal'»— Nietzsche declara que la grandeza del intelecto humano es tal sólo presuponiendo el punto de vista humano: «Si pudiéramos entendernos con el mosquito, llegaríamos a saber que también él flota por el aire con este pathos, y se siente el centro volante de este mundo» (KSA I 875). Ese sentirse así, es decir, esa verdad del individuo es una representación del intelecto: tanto del hombre como del mosquito. Por tanto, Nietzsche saca la conclusión de que el intelecto es «un medio para conservar al individuo» que «despliega sus fuerzas principales en la ficción (Verstellung)» (KSA I 876). En Ueber Wahrheit und Lüge, el tema de la ficción antropocéntrica se desarrolla en relación con el lenguaje; en las obras sucesivas, Nietzsche retoma dicho argumento en otros contextos. En particular, en el aforismo 14 de Der Wanderer und sein Schatten — que lleva al título, ya de por sí emblemático, Der Mensch, der Komödiant der Welt-Nietzsche acerca el tema al argumento teológico. En este aforismo es la hormiga la que ejerce el papel ejercido anteriormente por el mosquito ${ }^{11}$. Después de argumentar que sólo el aburrimiento puede haber empujado a Dios a crear al hombre con el fin de procurarse la diversión cruel indispensable para entretener su propia soledad y que, por tanto, no existe razón por la que el hombre deba considerarse el fin de la creación, Nietzsche concluye:

Tal vez la hormiga en el bosque se imagina, de forma igualmente poderosa, que es el objetivo y el fin de la existencia del bosque, como nosotros hacemos cuando, en nuestra fantasía, unimos casi involuntariamente a la destrucción de la humanidad la destrucción de la tierra (KSA II 549).

El mundo de la hormiga, es decir, el mundo visto desde la perspectiva de la hormiga, representa para Nietzsche el mundo privado de la perspectiva del hombre; representa un mundo pensado prescindiendo del sistema de los fines atribuibles al hombre.

Así pues, la hormiga es la actriz que quiebra definitivamente el sistema de la teleología que a Nietzsche se le presentaba como un problema desde su disertación juvenil Die Teleologie seit Kant (primavera 1868) y que, en aquella ocasión, creía haber podido resolver en términos antikantianos. «La finalidad de lo orgánico, la regularidad de lo inorgánico —escribió entonces— son introducidas en la naturaleza por nuestro intelecto». A la idea de que, en la naturaleza, todas las partes concuerdan como manifestaciones de una única voluntad, se opone «la terrible lucha de los individuos (que también manifiestan una idea) y de las especies». Para justificar esta teoría - que requiere una unificación «del mundo teleológico y del mundo no teleológico»— haría falta presuponer «una teleología sin lagunas, la cual no existe». De aquí la necesidad de una «critica de

11. El contexto narrativo también recuerda la fábula que abre Ueber Wabrheit und Lüge im aussermoralischen Sinne; Nietzsche habla ahora de «un número indeterminado de astros» que "presentan condiciones análogas a las de la tierra»: «iNuestra unicidad en el mundo! iAh, es cosa demasiado inverosímil!» (KSA II 549). 
la opinión de Kant», que consistirá en liquidar «la admisión de un mundo inteligible» (KGW I/4 551-552). La perspectiva de la hormiga — que el hombre no puede entender en cuanto vinculado a su propia perspectiva- es la apertura de esta laguna en la teleología.

Nietzsche continúa reflexionando sobre este tema y, poco a poco, aun no admitiéndolo explícitamente, esto se le presenta cada vez más como un problema exquisitamente kantiano. Ya en un fragmento (19[156]) datable entre la primavera de 1872 y el inicio de 1873 — un apunte extendido en vista del proyectado y nunca realizado Philosophenbuch - observa que «no podemos afirmar nada con respecto a la cosa en sí (vom Ding an sich), puesto que, bajo nuestros pies, hemos quitado el punto de apoyo que nos ha dado quien conoce (des Erkennenden), es decir, quien mide (des Messenden)».

Afirmar la existencia de una cualidad significa afirmar que la misma «existe para nosotros, esto es, a nuestra medida (gemessen)»: eliminando la medida (y, por tanto, también al hombre que mide) se elimina la cualidad. Pero, con esto, dado que el sistema de los fines no está en la naturaleza sino en nosotros, se pierde la posibilidad de conocer (y, por tanto, de medir) la naturaleza en su complejo, dado que la misma puede ser solamente el conjunto de los infinitos sistemas de los fines correspondientes a los infinitos seres naturales: "También la planta es un ser que mide (ein messendes Wesen)» (KSA VII 468).

La planta mudará pronto en nuestra hormiga, que ya encontramos incluida en un esquema argumentativo análogo, en un fragmento (10[D82]) del otoño de 1880 (del periodo, pues, al que se remonta la elaboración de Morgenröthe) en el cual Nietzsche se pregunta: «Un mundo sin sujeto, ¿es posible pensarlo (kann man sie denken)?»; lo que equivaldría a quitar de debajo de los pies el punto de apoyo de quien conoce y que impide cualquier afirmación sobre la cosa en sí. Pensar un mundo sin sujeto quiere decir pensar el mundo sin el sujeto que lo piensa: si esto es o no la misma cosa que el noúmeno kantiano es una cuestión que debe valorarse atentamente. Una primera respuesta nos dice que, según Kant, la cosa en sí puede pensarse con el intelecto pero no puede conocerse, puesto que conocemos solamente aquello que se nos da en la intuición empírica. $\mathrm{Si}$, por tanto, el sujeto es, ante todo, un sujeto sensible, la pregunta de Nietzsche parecería tener, desde un punto de vista kantiano, una respuesta negativa. Con todo, en la Kritik der reinen Vernunft —en el capítulo que concluye la «Analítica de los principios»- Kant distingue un noumenon negativo y un noumenon positivo. Este último indica una cosa que no es objeto de nuestra intuición sensible y que, por tanto, debe ser objeto de una intuición intelectual «que, sin embargo, no es la nuestra (die aber nicht die unsrige ist) ${ }^{12}$ ». El noumenon positivo, dado que prescinde de la sensibilidad y, por tanto, del sujeto, sería un objeto indeterminado y no determinable: sería (traducido en términos nietzscheanos) un mundo sin el sujeto que lo piensa. Con todo, prosigue Kant, admitiendo que sea posible que se den entes inteligibles desprovistos de cualquier relación con nuestra intuición sensible, en cuanto que los conceptos «de nuestro intelecto» (unsere Verstandbegriffe) son «simples formas del pensamiento para nuestra intuición sensible», éstos no podrán nunca «alcanzar» (reichen) dichos entes inteligibles.

12. I. Kant, Crítica de la razón pura, ed. de P. Ribas, Madrid: Alfaguara, 1988, p. 270. 
Así pues, el noumenon puede entenderse sólo en sentido negativo ${ }^{13}$, en su pura y simple oposición a los phaenomena: si éstos indican los objetos como entes sensibles - considerados por tanto según el modo en el que los intuimos-, los noumena serán aquellos mismos objetos considerados, sin embargo, en su naturaleza misma, pensados «simplemente por medio del intelecto», por tanto, como entes inteligibles ${ }^{14}$. La contradicción que parece anidar en el concepto de noumenon - puesto que éste es, en cualquier caso, el producto de un intelecto cuyos conceptos se determinan por la sensibilidad, pero que es, contemporáneamente, «una cosa en sí misma» (ein Ding an sich selbst) pensada por un intelecto puro- queda resuelta por Kant con el bien conocido argumento de la función exclusivamente crítico-reguladora de la cosa en sí: ésta debe impedir que la intuición sensible se extienda hasta las cosas que están más allá de la esfera sensible, hacia cuyo ámbito, que debe permanecer «vacío» (leer), puede extenderse el intelecto mismo solo en modo "problemático» (problematisch). De aquí la famosa conclusión: «El concepto de noumenon es simplemente un concepto-límite (Grenzbegriff) que sirve para circunscribir la pretensión de la sensibilidad y, por tanto, es sólo de uso negativo» ${ }^{15}$.

Así pues, no podemos pensar en la cosa en sí como si fuera un ente determinado: su incognoscibilidad es la inmediata consecuencia de esta imposibilidad. En el fragmento de Nietzsche que estamos examinando, sin embargo, parece ser precisamente ésta la tentativa llevada a cabo: el mundo sin sujeto se vuelve objeto de una determinación. Lo que significa que se pasa de la existencia de la cosa en sí (el mundo sin sujeto) a su conocimiento y que, consecuentemente, la cosa en sí se determina a través del conocimiento, que no puede ser otro que el conocimiento sensible. El resultado es que la cosa en sí se reconduce a la apariencia (sensible). Es decir, se infringe el mandato kantiano según el cual la intuición sensible no debe extenderse a los noumena. Pensar en un mundo sin sujeto equivaldría para Nietzsche a anular «de un golpe» toda la vida; pero por qué, se pregunta, una vez eliminado el sujeto «etodo lo demás no podría continuar moviéndose tranquilamente como lo vemos ahora (wie wir es jetzt sehen)?». Si los colores son «subjetivos» —es decir, si se perciben subjetivamente- nada nos prohíbe suponerlos como «objetivamente pensables»; pero esta objetividad resulta después idéntica a su percepción subjetiva sensible, o sea, a su apariencia: «La posibilidad de que el mundo se parezca al que se nos aparece (die uns erscheint) no queda en absoluto eliminada, cuando reconocemos los factores subjetivos». No se puede, por tanto, «eliminar el sujeto con el pensamiento»-lo que equivale, para Nietzsche, a «querer representarse (vorstellen) el mundo sin sujeto»- porque eso significaría «representar sin representación» (ohne Vorstellung vorstellen). La determinación (sensible) de la cosa en sí, al final, quita de en medio precisamente esta última para dejar sitio a «cientos de miles de representaciones subjetivas». Con esto queda zanjado el antropocentrismo: si se elimina con el pensamiento el mundo humano, todavía queda «el de las hormigas». Así pues, ¿esto significaría que dependería de la hormiga, en dicho caso, la existencia de la vida y del mundo? «Sí, el valor de la existencia depende del ser sensible (an

13. Ibid., p. 272.

14. Ibid., p. 273 .

15. Ibid., p. 272. 
den empfindenden Wesen). Y para los hombres, existencia y valor de la existencia son, a menudo, una sola y misma cosa» (KSA IX 431-432).

Esta conclusión suena como una radicalización de la posición kantiana, o mejor dicho, una extensión de dicha posición más allá del mismo Kant. En la frase que acabamos de leer, que concluye el fragmento, Nietzsche revela abiertamente su fuente: la Geschichte des Materialismus de Friedrich A. Lange. En efecto, Lange afirma: «En el mundo de los fenómenos (Erscheinungswelt), echan raíces las ideas de valor, de acuerdo con las cuales encontramos que aquí hay un juego insignificante y allá un acto serio y superior» ${ }^{16}$. Esta conexión entre el problema de los valores y la dimensión de la existencia —que se apoya sobre su común enraizamiento en el mundo fenoménico y, por tanto, en la esfera sensible- tiene su presupuesto en la resolución de la cosa en sí en el fenómeno, que representa la clave de la interpretación radical de Kant. Según Lange, no sólo la cosa en sí es incognoscible, ni siquiera podemos decir que exista: se trata de una pura hipótesis de nuestro intelecto, cuya actividad está enteramente determinada por los fenómenos dado que «nuestro mundo no puede ser otra cosa que un mundo de la representación (eine Welt der Vorstellung)»; si, por tanto, nos preguntamos donde está el fundamento de las cosas, la respuesta no puede ser otra que «en los fenómenos» (in den Erscheinungen). La cosa en sí resulta, al final, una representación de nuestro intelecto y su necesidad radica en la organización de esto, precisamente en el principio de causalidad. En otras palabras, ésta se revela como la causa (supuesta como simple hipótesis) del mundo de los fenómenos. Y, con esto, se sustrae, dejando espacio en su lugar al mundo de los fenómenos: "Cuanto más se volatiliza (verflüchtigt) la 'cosa en sî' y se reduce a una simple representación, más realidad adquiere el mundo de los fenómenos» ${ }^{17}$.

Como es bien sabido, Nietzsche fue un lector entusiasta y precoz del libro de Lange, del que compró una copia de la primera edición de $1866^{18}$. Como demuestra la carta a Carl von Gersdorff, escrita a finales de agosto del mismo año, que resume por puntos la interpretación kantiana de Lange, se puede decir que la lectura nietzscheana de la cosa en sí es enteramente mediada por aquella interpretación. En perfecta línea con Lange, Nietzsche define el concepto de la cosa en sí como el producto, madurado por simple oposición (respecto del mundo sensible), de nuestra "organización»: no podemos por tanto decir si esto «tiene algún significado más allá de nuestra experiencia» (KSB II 160). Nietzsche entiende de manera ejemplar cuán importante es, en Lange, la mediación de Schopenhauer, cuya obra fundamental había leído el año anterior. En efecto, que la cosa en sí no pueda darse sino como representación es, de hecho, una idea de Schopenhauer. Y schopenhaueriana es la consecuencia que Nietzsche extrae: el noumeno puede darse inmediatamente sólo en el arte. Si Lange piensa que los filósofos deben dejarse «libres», entonces «el arte es libre incluso en la esfera de

16. F. A. Lange, Geschichte des Materialismus und Kritik seiner Bedeutung in der Gegenwart [1866], ed. e introd. de A. Schmidt, Frankfurt a. M.: Suhrkamp, 1974, libro II: Geschichte des Materialismus seit Kant, p. 509.

17. Ibid., p. 498.

18. Véase al respecto J. Salaquarda, «Nietzsche und Lange»: Nietzsche-Studien 7 (1978), 236. Salaquarda resume la posición del «criticismo radical» en la tesis «según la cual todo lo que puede ser conocido por nosotros pertenece al mundo de las apariencias» (ibid.). 
los conceptos»; y entonces, «incluso ateniéndonos a este rígido principio crítico, nos queda siempre nuestro Schopenhauer, es más, se convierte para nosotros en algo más. Si la filosofía es arte, incluso Haym debe esconderse ante Schopenhauer» (ibid.).

Con esta homologación entre filosofía y arte, Nietzsche se abre un camino en el que se reencontrará dieciséis años después: esta filosofía que es arte es, de hecho, la definición de una ciencia que podrá definirse como fröhlich.

Mas esta gaya ciencia no se limita a los confines del libro que lleva este título. La definición más cumplida e icástica de esta idea la encontramos, de hecho, en aquel Versuch einer Selbstkritik que sustituye el Vorwort an Richard Wagner en la tercera edición de Geburt der Tragödie: «ver la ciencia con la óptica del artista, y el arte, en cambio, con la de la vida...» (KSA I 14). Éste es el programa de una gaya ciencia pensada como "arte de la filosofía», y el título mismo "es un título poético para una obra filosófica» ${ }^{19}$.

\section{VERDAD Y PERSPECTIVA}

Habiéndonos forjado las herramientas necesarias, podemos ahora volver a examinar los contenidos específicos de la jovialidad (gay saber). Es decir, podemos retomar la pregunta respecto a lo que, específicamente, nos lleva a la risa. Esta jovialidad es, en realidad, el resultado de aquella profunda y radical instancia de verdad que es la esencia de la ciencia misma. Ya sabemos que esta instancia de verdad conduce a considerar la verdad misma como la enunciación de un individuo que presupone, por eso mismo, la infinidad de las enunciaciones individuales. Por tanto, querer considerar la verdad en su totalidad e integridad es empresa vana e inane que no puede no suscitar la risa en quien se haya justamente convencido de que la verdad en su totalidad es sólo el conjunto infinito de las enunciaciones individuales. Es lo que Nietzsche sostiene en el primer aforismo de la Fröhliche Wissenschaft, cuyo análisis retomamos. Esa «ilimitada abyección de mosca y rana» nuestra resultaría sólo a quien supiera mofarse de nosotros como individuos, "como requeriría la verdad»; pero la enunciación de este punto de vista superior no podría después descuidar el ser ella misma la enunciación de un individuo y, por tanto, su primer resultado es la reducción del horizonte de la instancia veritativa. El hiato entre esta instancia y la conciencia de la dimensión del individuo es exactamente lo que mueve a la risa: "Reír de nosotros mismos como deberíamos, si quisiéramos reír partiendo de toda la verdad (um aus der ganzen Wahrheit heraus zu lachen)»(KSA III 370). Para llegar a esto, hace falta ese «sentido de la verdad» (Wahrheitssinn) o ese «genio» (Genie) que, hasta ahora, ni siquiera «los mejores» (die Besten) y «los más dotados» (die Begabtesten) han tenido. Cuando estas facultades se adquieran, se inaugurará el tiempo de una nueva humanidad y de una nueva ciencia:

19. W. Stegmaier, «Gaia scienza, arte della filosofia», ponencia presentada en el congreso «Verità e prospettiva in/a partire da Nietzsche», Macerata, 2-3 de diciembre de 2004 (de próxima publicación en F. Totano [ed.], Verità e prospettiva in/a partire da Nietzsche, Roma: Carocci) (las citas se refieren a la p. 1 del texto mecanografiado). 
¿Quizás haya todavía un porvenir también para la risa! Será cuando la máxima «la especie es todo (die Art ist Alles), uno es siempre ninguno» — se habrá encarnado en la humanidad, y a cada uno estará abierto en todo momento el acceso a esta última liberación e irresponsabilidad (Unverantwortlichkeit). Quizás la risa se habrá entonces aliado con la sabiduría, quizás entonces habrá, por lo menos, una «gaya ciencia» (ibid.).

El punto de vista que se recoge en la máxima die Art ist Alles representa manifiestamente la perspectiva biológica, el punto de vista de la naturaleza que tiene predilección por los grandes números en los que los individuos son solamente los elementos de la masa: esa naturaleza que garantiza la supervivencia de la especie mediante la generación de multitud de organismos individuales quedando indiferente ante sus destinos individuales. Es, en pocas palabras, el punto de vista del mosquito, de la hormiga, de la mosca y de la rana puesto al mismo nivel del punto de vista de la humanidad ${ }^{20}$.

Resumiendo, la «gaya ciencia» representa una consideración de la naturaleza liberada (i«esta última liberación»!) de cualquier teleología: una naturaleza considerada prescindiendo de ese sistema de los fines que es creación exclusiva humana y que sobreentiende, tal como Nietzsche subraya en la parte central del aforismo, una interpretación moral. Es, de hecho, el «teórico de la moral» (der ethische Lehrer), es decir, el "teórico de la finalidad de la existencia» (der Lehrer vom Zweck des Daseins), el que hace posible que «lo que acontece siempre y necesariamente, por sí mismo y sin objetivo alguno", se presente al contrario a nosotros como "hecho en vista de un objetivo (auf einen Zweck hin gethan) y resulte plausible al hombre como razón y mandamiento último» (KSA III 371).

De este modo, se hace evidente que todo lo que el hombre ha ubicado bajo el título de "conocimiento" debe entenderse como el proceso que el individuohombre ha elevado a valor universal, a pesar de quedar invencible e inexpresadamente ligado a la propia naturaleza individual. En consecuencia, nuestro conocimiento no es el resultado de una actividad de la especie-hombre sino una subrepticia subjetividad trascendental que es el sueño — humano, demasiado humano- de un individuo que quiere separar de sí mismo la propia dimensión biológica. A la luz de esta consideración, cada conocimiento se muestra perspectivista y la misma historia del conocimiento humano se desvela como necesidad de confirmar la imagen que el hombre se ha creado de sí mismo.

Éstos son los temas que Nietzsche afronta en el libro V de Fröhliche Wissenschaft. En el aforismo 354 (Vom Genius der Gattung), Nietzsche contrapone una «conciencia animal» a la conciencia humana, de la que se sirve como clave genealógica para comprender la naturaleza de la conciencia individual. Esta última derivaría de la «naturaleza comunitaria y gregaria» (Gemeinschaftsund Herden-Natur) del hombre, o sea, del hombre considerado en primer lugar como animal humano y «animal social» (sociales Thier) (KSA III 592). El desarrollo de la conciencia y del lenguaje avanzan al unísono dado que descienden

20. Remarcando la continuidad de la reflexión nietzscheana sobre este tema, se puede observar que el argumento de la «irresponsabilidad» recuerda con fuerza la observación que abre la Segunda intempestiva: la celebración de la inocencia del animal que vive «atado brevemente con su placer y dolor, agarrado, es decir, al poste del instante», mientras que el hombre se soprende «de no poder aprender a olvidar y de estar continuamente atado al pasado» (HL, KSA I 248). 
de la necesidad de establecer «una red de conexión entre hombre y hombre»: sintiéndose en peligro, el animal humano pide la ayuda de sus semejantes; ayuda que «el hombre solitario, el hombre bestia de presa» no habría necesitado (KSA III 591). Sigue la exigencia de reducir la realidad a sistema de signos con el que comunicarse; lo que presupone «tomar conciencia de nuestras impresiones sensibles, la fuerza de poder fijarlas y de sacarlas, por así decirlo, fuera de nosotros» para poder trasmitirlas «a otros mediante signos» (KSA III 592). La autoconciencia, es decir, la autopromoción del hombre a sujeto, no es más que el último paso en este proceso: en su origen está la necesidad de interpretar el mundo para servir al propósito de la conservación de la especie. Explicar de este modo el nacimiento de la conciencia significa observarla desde una perspectiva distinta, precisamente, la de la conciencia animal: «Éste es el verdadero fenomenalismo y perspectivismo (Phänomenalismus und Perspektivismus) tal como lo entiendo yo». Siguiendo el análisis del lenguaje iniciado con Ueber Wahrheit und Lüge, Nietzsche estigmatiza el empobrecimiento del mundo reducido a signo, traducido en lenguaje que elimina las diferencias entre ente y ente. Y, dado que lenguaje y conciencia corresponden a la misma necesidad, «todo lo que se vuelve consciente se convierte, por esa misma razón, en plano, exiguo, relativamente estúpido, genérico, signo, signo distintivo del rebaño». Con esto, se destruye la mitología idealista de la conciencia y del sujeto. Lo que interesa a Nietzsche no es ni «la oposición entre sujeto y objeto» («esta distinción la dejo a los teóricos del conocimiento»), ni «el contraste entre 'cosa en sî' y fenómeno", sino lo que queda después de esta destrucción, el único fenómeno de este fenomenalismo perspectivista: la conciencia animal - la conciencia de la especie- que ha eliminado la conciencia individual. «Nosotros 'sabemos' (o creemos, o nos imaginamos) - concluye Nietzsche- precisamente tanto cuanto puede ser provechoso saber en el interés del rebaño humano, de la especie» (KSA III 593).

Sin embargo, sería errado pensar que, de este modo, Nietzsche se abre a una especie de relativismo en el que la perspectiva humana individual se limita a perder la propia centralidad frente a una conciencia animal más general y originaria. Esto sería posible sólo permaneciendo en el horizonte de esa centralidad incluso cuando ésta viese reducido su propio valor. La conciencia de la especie se presenta, más bien, como un horizonte negativo que el hombre no puede, de hecho, asumir como un dato positivo, que no puede reconducir a la dimensión del hecho. Ella vincula todavía más al individuo a la propia perspectiva individual, más allá de la cual puede solamente advertir un infinito como margen negativo. Así escribe Nietzsche en el aforismo 374 (Unser neues «Unendliches»):

El intelecto humano no puede evitar verse a sí mismo bajo sus formas perspectivistas y solamente en ellas. No podemos ver más allá de nuestro ángulo: es una curiosidad desesperada el querer saber qué otras especies de intelecto y de perspectiva podría haber todavía (KSA III 626).

Todo lo que el hombre puede hacer frente a esta percepción negativa es abandonarse, una vez más, a la risa: la "presunción de decretar desde nuestro ángulo que sólo a partir de dicho ángulo se pueden tener perspectivas» no puede parecernos ya más que «ridícula» (lächerlich). Lo que queda detrás de nuestro ángulo no puede explorarse y se presenta, precisamente, como «nuestro nuevo 
infinito». Un «mundo ignoto» que podríamos estar tentados de nuevo de divinizar, como ya habían hecho los antiguos, si no fuera porque aquella advertida existencia del mundo de las hormigas nos ha puesto al corriente de cuantas «posibilidades no divinas de interpretación» están comprendidas en ese infinito; y, sobre todo, de que, entre las mismas, figura «nuestra interpretación humana, incluso demasiado humana, que conocemos» (KSA III 627).

Este «nuevo infinito» queda, por tanto, como una entidad meramente negativa, que asume un sentido puramente limitativo y regulador en relación con nuestra posibilidad de conocer. (¿Qué otra cosa, en el fondo, si no una reedición, en términos más radicales, de la función que Kant asigna a la cosa en sí?) Pensar en este infinito positivamente y, por tanto, ponerlo como objeto de la conciencia, es la tarea sobre la cual se ha medido la presunción de la ciencia moderna. La transformación de esta entidad negativa en hecho no es diferente de la tentación de una nueva divinización denunciada por Nietzsche. Sale a la luz, de este modo, el fundamento metafísico de la ciencia moderna: aquella metafísica «aún necesaria» en la que se apoya «aquel vehemente anhelo de certeza (Verlangen nach Gewissheit), que hoy en gran medida encuentra una salida científico-positivista, el anhelo de querer poseer absolutamente algo de modo firme (fest haben)» (aforismo 347, «Die Gläubigen und ihr Bedürfniss nach Glauben», KSA III 581-582). Este fest haben, este anhelo de certeza puede apoyarse solamente en la reducción de la infinidad de interpretaciones posibles a una única: aquella gracias a la cual el infinito se presenta como hecho y el intérprete, como sujeto que interpreta. El contexto que hemos trazado es aquel en el que se inserta el célebre fragmento (7[60], finales 1886-primavera 1887: contemporáneo, por tanto, a la segunda edición de Fröhliche Wissenschaft) en el cual Nietzsche toma posición contra el positivismo: "Contra el positivismo, que se queda en el fenómeno 'sólo hay hechos', yo diría, no, precisamente no hay hechos, sólo interpretaciones. No podemos constatar ningún factum 'en sî': quizás sea un absurdo querer algo asî̀ ${ }^{21}$.

La supremacía que la interpretación conquista sobre los hechos, sin embargo, no reenvía a la actividad de un sujeto que interpreta; la eliminación del hecho excluye incluso el sujeto que le da este sentido ${ }^{22}$, y promulgar la supremacía de la interpretación tiene un significado mucho más radical que el de una simple reducción de la perspectiva del sujeto:

«Todo es subjetivo", decís vosotros: pero ya eso es interpretación, el sujeto no es algo dado sino algo inventado y añadido, algo puesto por detrás (etwas Hinzu-Erdichtetes, Dahinter-Gestecktes). - ¿Es en última instancia necesario poner aún al interprete detrás de la interpretación? Ya eso es invención (Dichtung), hipótesis ${ }^{23}$.

Decir que el mundo es «interpretable» (deutbar) significa decir que es interpretable «en modos diversos» (anders), significa que es susceptible de infinitas posibilidades no divinas de interpretación; es decir, significa que el mundo «no

21. KSA XII 315 (FP IV p. 222).

22. Cf. el frag. 2[149] del otoño 1885-otoño 1886: «Una 'cosa en sí', algo tan equivocado como un 'sentido en sî', un 'significado en sî'. No hay un 'hecho' en sí, sino que siempre tiene que introducirse primero un sentido para que pueda haber un hecho» (KSA XII 140); cf. FP IV 123.

23. Ibid. (FP IV 222). 
tiene un sentido detrás de sí, sino innumerables sentidos. 'Perspectivismo'» (KSA XII 315). Este perspectivismo abre a las reflexiones que Nietzsche elabora, en ese mismo período, sobre la voluntad de poder. Son nuestras «necesidades» (Bedürfnisse) y nuestros «impulsos» (Triebe) los que interpretan el mundo: "Cada impulso es una especie de ansia de dominio (Herrschsucht), cada uno tiene su perspectiva, que quisiera imponer como norma a todos los demás impulsos» (ibid.). En un fragmento (2[148]) de aproximadamente un año antes (otoño 1885-otoño 1886) Nietzsche había apuntado:

La voluntad de poder interpreta: en la formación de un órgano se trata de una interpretación; la voluntad de poder delimita, determina grados, diferencias de poder [...] En verdad la interpretación es ella misma un medio para hacerse señor de algo. El proceso orgánico presupone un permanente INTERPRETAR ${ }^{24}$.

Del mismo modo que la voluntad de poder no es la voluntad de un sujeto, tampoco la interpretación se pone como predicado de un sujeto. En un fragmento del mismo periodo (2[151]), Nietzsche excluye que se deba preguntar "¿entonces, quién interpreta?", dado que «el interpretar mismo, en cuanto una forma de la voluntad de poder, tiene existencia (pero no como un 'ser', sino como un proceso, un devenir) como un afecto (Affekt)» ${ }^{25}$.

Como ha observado Wolfgang Müller-Lauter, esto remedia el malentendido por el que «se podría pensar que la voluntad de poder [...] es un sujeto del cual se puede predicar la interpretación», y podemos concluir «que las voluntades de poder se confrontan como interpretaciones que cambian continuamente» ${ }^{26}$. Llevando voluntad de poder e interpretación bajo el signo común del perspectivismo llegamos, pues, a su clarificación esencial y recíproca.

[Traducción de Giuseppe Vinti y Luca Giancristofaro Universidad de Valencia]

24. KSA XII 139-140 (FP IV 122).

25. KSA XII 140 (FP IV 123).

26. W. Müller-Lauter, «Nietzsches Lehre vom Willen zur Macht»: Nietzsche-Studien 3 (1974), 43-44. 